\title{
THE OPTIMAL RATE OF DECLINE OF AN INEFFICIENT INDUSTRY
}

\author{
Bruce A FORSTER \\ University of Guelph, Guelph, Ontarlo, Canada \\ Ray REES* \\ Unwersity College, CardIf CFI IXL, UK
}

Received October 1981, revised version received May 1983

\begin{abstract}
This paper considers the problem of the optimal time path of contraction of an industry which has been hit by foreign competition, and shows that in general, along the optımal path, a production subsidy is warranted The optimal subsidy trades off the benefit of unemployment in speeding up the approach to the new long-run equilibrium against the cost of lost output in the 'inefficient' industry The dynamic shadow price of labour in this industry is also derived and shown to be always positive, though below the industry wage rate
\end{abstract}

\section{Introduction}

This paper is concerned with the following problem a major industry becomes, as a result of foreign competition, unprofitable at its current output The output level at which it is viable is considerably below the existing one How rapidly, therefore, should it contract?

In the policy debates surrounding particular instances of this problem, for example the steel, shipbuilding, motor car and coal industries in the United Kingdom, two extreme positions often tend to be adopted The protectionist position is to use import controls, tarifs or production subsidies to maintain as far as possible the status quo The frec trade position is to allow the market mechanism to bring about the resource reallocations which the change in competitive conditions has necessitated In practice, an intermediate pragmatic policy is often followed production subsidies (possibly facilitated by taking the industry into public ownership, if it is not already a public enterprise) and trade barriers are used to moderate, but not negate, the effects of the foreign competition That $1 \mathrm{~s}$, measures are taken to slow the transition to the new equilibrium

\footnotetext{
*Versions of this paper have been presented at semınars at Queen's University, Kingston, and at the Universities of Guelph, McMaster, and Waterloo in Ontano, Canada, and Sheffield, Swansea, and Bath in the UK We are grateful to the participants in those seminars and to the referees for many helpful comments
} 
Such a policy tacitly recognises the inefficiencies inherent in each of the extreme positions To seek to maintain the status quo implies a continuing loss in real national income arising from the failure to adjust To allow the unimpeded operation of market forces results in higher levels of unemployment - and therefore losses of output - which may be brought down only very slowly, at a rate dependent on the extent of wage rigidity and the costs of relocation and re-training of labour

The analysis of this paper provides support for the pragmatic, intermediate position The view underlying the analysis is that the problem is essentially one of dynamic optimisation, and therefore cannot be successfully solved with the standard static models ${ }^{1}$ Thus, we seek to characterise explictly the optimal contraction path for an industry which is initially 'inefficient', in a sense to be defined

An important concept in many applied cost-benefit studies in this area is the 'shadow price of labour' [see Jenkıns and Montmarquette (1979), N B P I (1970), and HM Treasury (1977)] An interesting joint product of our analysis is a characterisation of a dynamic shadow price of labour, given by the marginal social opportunity cost of labour along the optımal adjustment path The important qualitative property of this is that while in general it is below the wage rate in the declining industry, it is significantly above zero (even 1gnoring the question of workers' valuation of leisure) as long as unemployment influences the process of resource reallocation in the economy

In the following section we set out the basic model Section 3 then seeks to give some insight into the problem by carrying out a comparative statics analysıs using a diagrammatic technique developed by Neary $(1978,1981)$ Section 4 then carries out the dynamic optimisation and the concluding section discusses the policy significance of the results

\section{The model}

There are several senses in which an industry may be said to be 'inefficient' First, it may be operating with a technology which produces a given output with more of at least one input and no less of any other than an alternative known technology Secondly, it may be using the best technology but with non-cost-minimising input levels, and in particular excess labour Thirdly, although cost-minimising with respect to the bestknown technology it may be over-expanded relative to the output which is viable at prevaling (world) market prices

It seems true to say that all three types of inefficiency have been present in

\footnotetext{
${ }^{1}$ As far as we are aware, only one previous paper takes a dynamic approach to this type of problem see Lapan (1976) We discuss the relationship of Lapan's analysis with that offered in this paper in section 4 below
} 
some, and at least one of them in all, of the industries in the $U K$ whose decline has caused major policy problems - motor cars, steel, coal, shipbuilding and textıles On the other hand, the economic (as opposed to the political) solution of the first two types of problem is straightforward the economy is operating in the interior of its production set and everyone (including any displaced workers) can be made better off by correcting the inefficiency no loss of output is involved In the third case, on the other hand, there is a genuine policy trade-off In any economy in which labour cannot be centrally directed, unemployment is part of the mechanism of adjustment and so there is a trade-off between the extent of unemployment (and associated output losses) and the speed of adjustment In order to concentrate on this problem we take into account in this paper only the third type of inefficiency, and this determines our choice of formal model

We assume a two-good, two-input economy which is a price-taker in world trade It imports good $Y$ and exports good $X$ It produces each good with standard neo-classical production functions under constant returns to scale The economy is initially in full neo-classical equilibrium the two inputs, labour $(L)$ and capital $(K)$ are fully employed, the wage rates in each sector, $w_{x}$ and $w_{y}$, are equal to each other and to the marginal value product of labour in each sector and likewise the rental rates on capital, $r_{x}$ and $r_{y}$, are equal both to each other and to the marginal value product of capital in each sector There is perfect competition in both sectors and so profits are zero The production equilibrium can be described therefore by the following six equations

$$
\begin{aligned}
& \gamma^{x}\left(w_{x}, r_{x}\right)=1, \\
& \gamma^{y}\left(w_{y}, r_{y}\right)=p, \\
& \gamma_{w}^{x}\left(w_{x}, r_{x}\right) X=L_{x}^{0}, \\
& \gamma_{r}^{x}\left(w_{x}, r_{x}\right) X=K_{x}^{0}, \\
& \gamma_{w}^{y}\left(w_{y}, r_{y}\right) Y=L_{y}^{0}, \\
& \gamma_{r}^{y}\left(w_{y}, r_{y}\right) Y=K_{y}^{0}
\end{aligned}
$$

Here $\gamma^{x}$ and $\gamma^{y}$ are the unit cost functions ${ }^{2}$ in $X$ and $Y$, respectively, $\gamma_{w}^{x} \equiv \partial \gamma^{x} / \partial w_{x}$, etc, ${ }^{3} X$ is the numeraire and $p$ is the (world) price of $Y$ in

\footnotetext{
${ }^{2}$ That is to say, the minimised cost of producing one unit of the corresponding output at the given input prices Given our assumption about production functions these unit cost functions are well-defined

${ }^{3}$ The derivative of the unit cost function of $X$ with respect to the wage (resp rental) gives the amount of labour (resp capital) required to produce one unit of $X$, and likewise for $Y$
} 
terms of $X, L_{x}^{0}$ and $L_{y}^{0}$ are respectively the labour supplies to $X$ and $Y$ in the initial equilibrium, $K_{x}^{0}$ and $K_{y}^{0}$ the corresponding capital supplies, and $X, Y$ denote the outputs, as opposed to consumptions, ${ }^{4}$ of the two goods Thus (1) and (2) are zero profit conditions, (3)-(6) input equilibrium conditions Because the economy is initially in full neo-classical equilibrium, $w_{x}=w_{y}$ and $r_{x}=r_{y}$ If we were to assume complete mobility of capital, then of course (4) and (6) could be summed and equated to $K^{0} \equiv K_{x}^{0}+K_{y}^{0}$, the economy's aggregate initial stock of capital Likewise, full labour mobility would imply that we could sum (3) and (5) and equate this to $L^{0} \equiv L_{x}^{0}+L_{y}^{0}$, the economy's aggregate labour supply But since we shall in this paper assume various kinds of factor immobility we take (3)-(6) as the general case

Suppose now that the price of the imported good, $p$, falls once and for all to a new level $\bar{p}$ This could be because there has been entry into the world market by a significant number of new low-cost producers We know that, as a result, this initial production equilibrium is inefficient $Y$ should contract and $X$ expand The problem we pose here is How rapidly should this reallocation take place?

\section{Diagrammatic analysis}

Fig 1 is an extension of a diagram constructed by Neary (1978) In fig 1(a) are plotted the factor price frontiers ${ }^{5}$ for $X$ and $Y$, respectively, where $F_{x}^{0}$ and $F_{y}^{0}$ correspond to the initial price $p$ and $F_{y}^{\prime}$ corresponds to the new price $\bar{p}$ Thus, $F_{x}^{0}$ shows the set of $\left(w_{x}, r_{x}\right)$ parrs which satisfy eq (1), and $F_{y}^{0}$ shows the set of $\left(w_{y}, r_{y}\right)$ pairs satisfying (2) At the initial equilibrium $E^{0}$ the intersection of the frontiers determines the wage and rental rates, $w^{0}$ and $r^{0}$ It is assumed, since we want to study the consequences of wage ngidity in $Y$, that this is the labour-intensive sector Hence, the slope of $F_{y}^{0}$, which is the capital-labour ratio in $Y$, is flatter than that of $F_{x}^{0}$ at the equilibrium

In fig 1(b) we show the equilibrium in the labour market $D_{x}^{0}$ is the initial demand curve for labour in $X$, with $L_{x}$ measured rightward from the origin $O_{x}$, and $D_{y}^{0}$ is the initial labour demand curve in $Y$, with $L_{y}$ measured leftward from the origin $O_{y}$. The initial equilibrium labour allocation at wage rate $w^{0}$ is then $L_{x}^{0}, L_{y}^{0}$

Fig 1(c) is a conventional Edgeworth-Bowley box, with labour along the horizontal side and capital on the vertical $O_{x} O_{y}$ is the locus of isoquant tangencies The initial equilibrium capital allocation is therefore $K_{x}^{0}, K_{y}^{0}$

When the price of $Y$ falls to $\bar{p}$, the factor price frontier $F_{y}^{0}$ in (a) undergoes a radial shift inward to $F_{y}^{\prime}$, with $F_{x}^{0}$ unchanged The new 'full equilibrium' is

\footnotetext{
${ }^{4}$ In fact, because the economy is assumed to be a price-taker in world trade, there is a separation between consumption and production and we proceed entirely in terms of the latter

${ }^{5}$ Mussa (1979) gives a thorough discussion of this diagram and applies it to illustrate a number of important theorems in international trade theory
} 


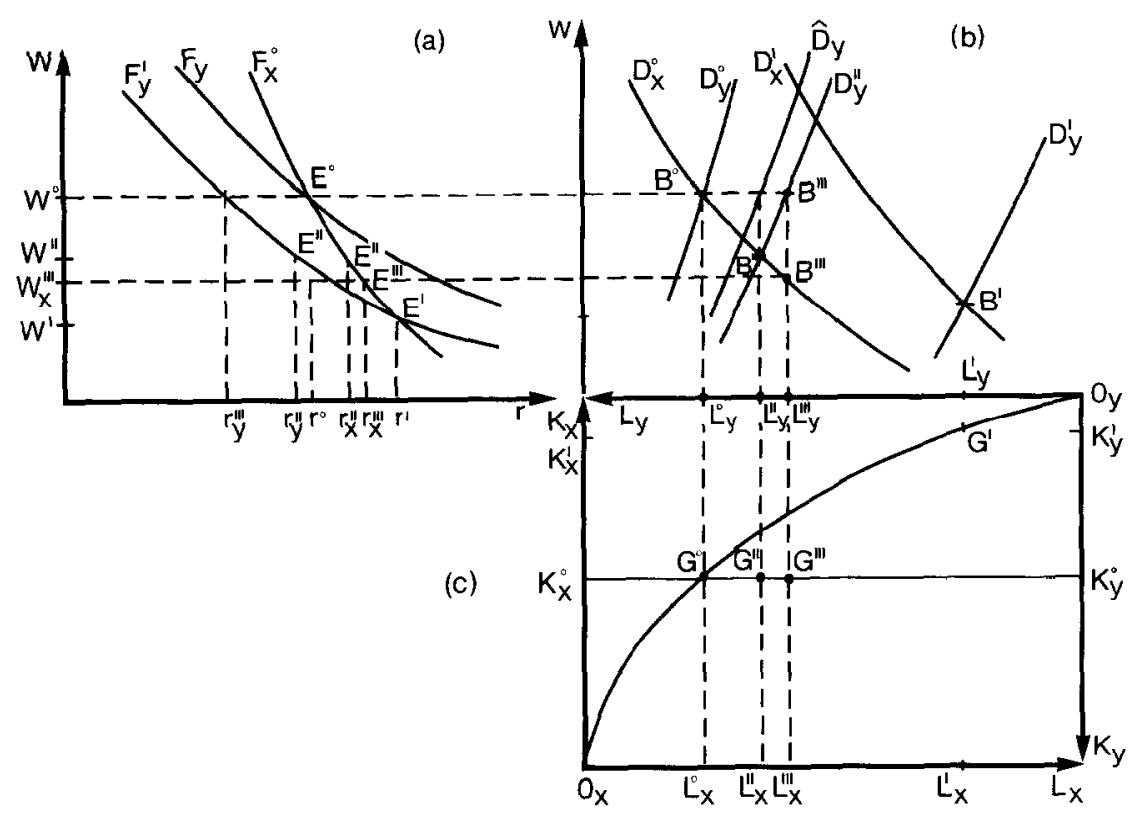

Fig 1

at $E^{\prime}$ with wage rate $w^{\prime}$ and rental $r^{\prime}$ In (b), the effect of the price fall is to shift the labour demand curve in $Y$ to $D_{y}^{\prime \prime}$ However, in the case where capital is fully mobile, capital as well as labour shifts from $Y$ to $X$, causing both labour demand curves to shift further and a final equilibrium is reached at $B^{\prime}$ Given that both inputs are fully mobile and factor prices flexible, therefore, the economy ends up producing at $G^{\prime}$ in (c), the new full neoclassical equilibrium

Now consider the sector-specific capital case (the analysis here is a mirror image of that carred out by Neary) All input adjustments are confined to the horizontal line $K_{x}^{0}, K_{y}^{0}$ in (c), since capital does not shift between sectors The new demand curve $D_{y}^{\prime \prime}$ in (b) gives a new labour market equilıbrium at $B^{\prime \prime}$, implying a labour allocation $L_{x}^{\prime \prime} L_{y}^{\prime \prime}$ The equilibrium wage rate $w^{\prime \prime}$ in (a) now implies unequal rental rates $r_{y}^{\prime \prime}$ and $r_{x}^{\prime \prime}$ in $Y$ and $X$, respectively We can establish the following inequalities among the proportionate rates of change ${ }^{6}$ (denoted by ${ }^{\circ}$ )

$$
\hat{r}_{y}<\hat{p}<\hat{w}_{y}=\hat{w}_{x}<0<\hat{r}_{x},
$$

which are reflected in the figure The sector-specific capital assumption implies that the economy is off its 'long-run' contract locus in (c), essentially

${ }^{6}$ For the method of deriving these inequalities, see Jones (1971) 
because the marginal value product of capital in $X\left(=r_{x}^{\prime \prime}\right)$ exceeds that in $Y\left(=r_{y}^{\prime \prime}\right)$ Over time, we would expect capital to be reallocated in response to this divergence in rental rates, but in the short to medium term the divergence will persist

As long as we have input price flexibility, the only question relating to dynamic adjustment is that of the speed with which the economy moves from $G^{0}$ to $G^{\prime \prime}$, which in turn is determined by the rate of response to factor price differentials Clearly, the faster this response the better, since every instant spent away from the new long-run equilibrium involves a loss of national output valued at world prices The only policy problem therefore is to speed up the rate of transfer of inputs

More interestıng and realistic problems arıse, however, when we recognise the possibility of input price, and in particular wage, rigidity If the wage rate $w_{y}$ is rigid downward, then the impact effects of the fall in $p$ is to cause unemployment in $Y^{7}$ We assume in this paper that workers in $Y$ are unionised and refuse to accept a wage cut, and so lay-offs result ${ }^{8}$ Thus, in fig 1(b) demand for labour in $Y$ at the rigid wage $w_{0}$ falls to $L_{y}^{\prime \prime}$, employment in $X$ remains at $L_{x}^{0}$, and unemployment of $L_{y}^{\prime \prime \prime}-L_{x}^{0}$ occurs Production of $Y$ falls to the point indicated by $G^{\prime \prime \prime}$ in (c), while no corresponding increase in output of $X$ takes place Thus, in (a) the rental rate in $Y$ falls to $r_{y}^{\prime \prime \prime}$

Assuming that the wage rate in $Y$ remains fixed at $w_{y}^{0}$, the burden of adjustment falls on the $X$-sector, which is taken here to be non-unionised The unemployed bid down the wage rate in $X$ until full-employment equilibrium is restored at $B^{\prime \prime \prime}$, with a wage rate of $w_{x}^{\prime \prime \prime}$ and rental $r_{x}^{\prime \prime \prime}$ Note that in the final (sector-specific capital) equilibrium $G^{\prime \prime \prime}$ in (c), output of $X$ is too large and that of $Y$ too small relative to the equilibrium with wage flexibility, $G^{\prime \prime}$ This represents an output inefficiency essentially due to the excess of the marginal value product of labour in $Y\left(=w_{y}^{0}\right)$ over that in $X$ $\left(=w_{x}^{\prime \prime \prime}\right)$ The economy is at a 'distorted equilibrium'

${ }^{7}$ By settıng $w_{y}=w_{y}^{0}=$ constant in (2), re-expressing (5) as

$$
\gamma_{w}^{y}\left(w_{y}^{0}, r_{y}\right) Y+U_{y}=L_{y}^{0},
$$

where $U_{y}$ is unemployment in $Y$ (initially zero), and carrying out the comparative statics of the system (1)-(6) with respect to a change in $p$, we can show that

$$
\hat{U}_{y}=-\left\{\sigma_{y}+\frac{\beta^{x}}{1-\beta^{x}} \sigma_{x}+\frac{\theta^{x}}{1-\theta^{x}}\right\} \frac{\hat{p}}{\theta^{y}}
$$

The change in $U_{y}$ is expressed as a proportion of the initial employment level in $Y, \sigma_{1}$ is the elasticty of factor substitution in sector $t=X, Y, \beta^{x}$ is the proportion of the economy's total capital installed in $X$ and $\theta^{t}$ is the share of capital in output of sector $l=X, Y$ Thus, with $w_{y}$ fixed, a fall in $p$ raises $U_{y}$ It is straightforward also to derive conditions for a 'magnification effect' $\hat{U}_{y}>\hat{p}$, though this does not seem to be of interest in the present context

${ }^{8}$ Alternatively, a labour contract may be in force which does not provide for wage adjustments in the event of output price fluctuations 
The appropriate choice of policy to correct this equilibrium distortion is well known ${ }^{9}$ By paying an output or wage subsidy to industry $Y$ the labour demand curve $D_{y}^{\prime \prime}$ can be shifted up to $\hat{D}_{y}$ in fig 1 (b) so as to lead to labour demand $L_{y}^{\prime \prime}$ at wage rate $w^{0}$ Note that there is no equivalent instrument or policy which can be applied to $X$ any policy which shifts $D_{x}^{0}$ leaving $D_{y}^{\prime \prime}$ unaffected alters the wage rate in $X$ but cannot achieve point $G^{\prime \prime}$ in (c) This is because increasing labour demand in $X$ cannot increase employment in $Y$

However, our concern is this paper is not with the question of the correction of the static distortion, but rather with the time-path of adjustment of the economy after the price change has taken place The market adjustment process takes place along the demand curve $D_{x}^{0}$ and is made at the cost of output losses and unemployment The question then arises of whether and how a dynamic policy can be formulated which produces a superior path of adjustment We now consider this question

\section{A dynamically optimal policy}

In the uncontrolled market cconomy the fall in the world price of the imported good results in a fall in its domestic production level and in the demand for labour Because the workers refuse to accept a wage cut, lay-offs result, and no further adjustments in this sector take place The unemployed steadily 'migrate' to the export good sector, and create an excess supply of labour there The wage rate in this sector, though sticky, is not rigid, and the pressure of excess labour supply gradually bids down the wage rate until full employment is restored Since in each industry the marginal value product of labour is equated to the wage rate, that in $X$ is lower than that in $Y$ and so the final equilibrium is a distorted one

We define the 'planner's problem' in this economy in the following way The planner sets as his ultimate aim or end-point the resource allocation which maximises national output at world prices, 1 e the point $G^{\prime \prime}$ in fig 1(c) The objective which determines the path he takes in getting there is to minimise the total cost of not being at that point, $1 \mathrm{e}$ the cumulative loss of potential national output along the adjustment path For simplicity we assume a zero discount rate in the main analysis (though we shall point out the implications of a positive discount rate once the basic results have been derived)

The instrument avalable to the planner is a production subsidy paid to the $Y$ industry, which is financed by lump-sum taxation (e $\mathrm{g}$ on the rents to capital in $X$ and $Y$ ) and which therefore is non-distortionary It is well known that such a subsidy is superior to a tariff since the latter creates a trade distortion A wage subsidy payable to the $Y$ industry can be shown to

\footnotetext{
${ }^{9}$ See Corden (1974)
} 
be an equivalent instrument to a production subsidy, so need not be explicitly considered A wage (or production) subsidy paid to the $X$-industry is a possibility which raises interesting issues in relation to the dynamic adjustment process assumed here, and so will be considered in section 5 below

In choosing the time-path of production subsidy, the planner is constrained by essentially the same kind of adjustment process which characterises the uncontrolled economy - he was to rely on unemployment to induce labour migration and bid down the wage rate in $X$ We adopt a very simple formalisation of this process a single parameter $\lambda$ represents both the effect of unemployment in $Y$ in inducing a shift of labour supply to $X$, and the effect of the excess labour supply to $X$ in bidding down the (sticky) wage rate $w_{x}$

One central result of the analysis is the following intervention by the planner will in general improve upon the uncontrolled market solution, and the optimal path involves trading off the benefit of unemployment in speeding up the adjustment process and increasing the value of total output agannst its cost in the form of loss of current output ${ }^{10}$ We now set out our model formally

Denoting the short-run profit functions in $X$ and $Y$ by $\pi^{x}\left(w_{x}\right)$ and $\pi^{y}\left(w_{y}\right)$, respectively, Hotelling's lemma yields the labour demand functions

$$
L_{x}=-\pi_{w}^{x}\left(w_{x}\right), \quad L_{y}=-\pi_{w}^{y}\left(w_{y}^{0}, p\right)
$$

The production functions can therefore be written

$$
X=f^{x}\left(-\pi_{w}^{x}\left(w_{x}\right)\right), \quad Y=f^{y}\left(-\pi_{w}^{y}\left(w_{y}^{0}, p\right)\right)
$$

(the constant capital terms have been suppressed)

Excess supply of labour in the economy is $-\left(L_{x}+L_{y}-L^{0}\right)$ Taking the parameter $\lambda$ to encapsulate both the rate at which unemployed workers in $Y$ transfer their ex ante supply to $X$, and the rate at which the wage rate in $X$

\footnotetext{
${ }^{10}$ This result was anticipated by Lapan (1976) However, our model differs from Lapan's in a number of respects He takes the wage rates in the two sectors to be always equal, even though there is no mechanism in his model by which this can be ensured Unemployment in $Y$ causes excess supply of labour in $X$, which is absorbed by means of a general wage subsidy Unfortunately, he does not derive the time-path of this subsidy directly, but infers it from the optımal paths of unemployment (the instrument) and labour supply in $X$ (the state variable) As a result the optımal tıme-path of the subsidy is specified in an incomplete and very cumbersome way and, where directly comparable, our results are the opposite of his Finally, Lapan adopts a 'fixed time horizon free end-point' formulation of the problem, which, though useful for the theoretical issues he is considering, has the undesirable result that the optimal time path does not converge to the point at which the value of national output at world prices is maximised even in 'the long-run', marginal value products of labour are not equalised across sectors It seems more reasonable to us to adopt a formulation which involves aiming at this point
} 
adjusts to excess labour supply, we have [using (8)] the simple adjustment equation

$$
w_{x}=\lambda\left[-\pi_{w}^{x}\left(w_{x}\right)-\pi_{w}^{y}\left(w_{y}^{0}, p\right)-L^{0}\right], \quad \lambda>0
$$

The strict convexity of the profit function applies

$$
\frac{\mathrm{d} \dot{w}_{x}}{\mathrm{~d} w_{x}}=-\lambda \pi_{w w}^{x}<0,
$$

and so that value $w_{x}^{*}$ which, for $p=\bar{p}$ equates aggregate demand and supply of labour, can easily be shown to be a globally stable equilibrium

The policy problem is that of choosing the value of a production subsidy $\tau \geqq 0$ to be paid to domestic producers, implying a producers' price $\bar{p}+\tau$ Consumers go on buying at the world price $\bar{p}$, and so there are no consumption distortions associated with this policy

The criterion we adopt is

$$
\min _{\{T, \tau(t)\}} \int_{0}^{T}[\hat{V}-V] \mathrm{d} t,
$$

where $V=X+\bar{p} Y$ is the value of national output at world prices and $\hat{V}$ is the maximum long-run sustainable value of output at world prices The criterion in (12) says that we seek a policy which achieves the best avallable sustainable equilibrium (subject to fixed sectoral capital stocks) with the minımum cumulative loss of national income in gettıng there The terminal time is also a variable in the optımisation process and is solved for endogenously

The fixed end-point $\left(\hat{\tau}, \hat{w}_{x}, \hat{V}\right)$ of the control problem is determined by solving

$$
\begin{gathered}
\max _{\left\{\tau, w_{x}\right\}} V=f^{x}\left(-\pi_{w}^{x}\left(w_{x}\right)\right)+\bar{p} f^{Y}\left(-\pi_{w}^{y}(\bar{p}+\tau)\right) \\
\text { s t } \quad-\pi_{w}^{x}\left(w_{x}\right)-\pi_{w}^{y}(\bar{p}+\tau)-L^{0} \leqq 0, \\
\quad \tau \geqq 0
\end{gathered}
$$

(We place the direct restriction on $\tau$ because we want to consider explicitly conditions under which $\hat{\tau}=0$ )

The Lagrange function is

$$
L\left(w_{x}, \tau, \alpha\right)=V-\alpha\left[-\pi_{w}^{x}\left(w_{x}\right)-\pi_{w}^{y}(\bar{p}+\tau)-L^{0}\right],
$$


and necessary conditions are

$$
\begin{aligned}
& \frac{\partial L}{\partial w_{x}}=-f_{L}^{x}+\hat{\alpha}=0, \\
& \frac{\partial L}{\partial \tau}=-\bar{p} f_{L}^{y}+\hat{\alpha} \leqq 0, \quad \hat{\tau} \geqq 0, \quad \hat{\tau}\left[\hat{\alpha}-\bar{p} f_{L}^{y}\right]=0, \\
& \frac{\partial L}{\partial \alpha}=\pi_{w}^{x}+\pi_{w}^{y}+L^{0} \geqq 0, \quad \hat{\alpha} \geqq 0, \quad \hat{\alpha}\left[\pi_{w}^{x}+\pi_{w}^{y}+L^{0}\right]=0
\end{aligned}
$$

We would naturally expect $f_{L}^{x}>0$ and so $\hat{\alpha}>0$ and the optımum involves full employment $\hat{\tau}>0$ implies $\bar{p} f_{L}^{y}=f_{L}^{x}$ We know from the diagrammatic analysis of the previous section that $\hat{\tau}=0$ implies $f_{L}^{x}<\bar{p} f_{L}^{y}$, and so a zero production subsidy cannot maximise the sustainable value of national output Hence, $\hat{\tau}>0$ in the final controlled equllbrium, so that marginal value products (at world prices) are equated across sectors

In the controlled equilibrium the optımal $\hat{\tau}$ raises labour demand in $Y$ to $\hat{D}_{y}$ in fig 1(a), and marginal value products of labour $f_{L}^{x}=\hat{w}_{x}$ and $\bar{p} f_{L}^{y} \equiv \hat{\omega}_{y}$ are equalised Note that in equilibrium, $\hat{\omega}_{y}$ can be defined as the shadow price of labour in $Y$, and is equal to the wage in $X$ In effect, then, the fixed end-point of the dynamic problem is the sector-specific capital equilibrium $G^{\prime \prime}$ in fig 1(c), with the value $\hat{\tau}$ precisely that which corrects the 'static distortion'

The optimal controlled adjustment path is then found by minımising (12) with $\hat{V}$ given, subject to the differential equation constraint (10), and again $\tau \geqq 0$ In order that a path $\left(\hat{\tau}(t), \hat{w}_{x}(t)\right)$ be optımal, it is necessary that there exist functions $H$ and $\psi(t)$ such that

$$
\begin{aligned}
& H=\hat{V}-V+\psi \lambda\left[-\pi_{w}^{x}-\pi_{w}^{y}-L^{0}\right], \\
& H_{\tau}=\left[\bar{p} f_{L}^{y}-\psi \lambda\right] \pi_{w p}^{y} \geqq 0, \quad \hat{\tau} \geqq 0, \quad H_{\tau}=0, \\
& \psi=-\left[f_{L}^{x}-\psi \lambda\right] \pi_{w w}^{x}, \\
& H(t)=H(\hat{T})=0
\end{aligned}
$$

If $\hat{\tau}(t)>0$ at $t<\hat{T},(20)$ implies

$$
\bar{p} f_{L}^{y}=\psi \lambda=\omega_{y}(t)
$$

where $\omega_{y}(t)$, is the 'dynamic shadow price of labour' At each instant on the adjustment path employment in $Y$ is such that the marginal value product of 
labour there is equated to its marginal social cost This latter, the term $\psi \lambda$, is the contribution unemployment in $Y$ makes to the desired adjustment of outputs, via its pressure on $w_{x}$ a small amount of unemployment not created means a little less pressure on the wage rate in $X$, hence a smaller expansion of employment and output there Thus, the optımal subsidy can be thought of as trading off the lost output arising from unemployment against the value of unemployment in generatıng the required resource reallocations in a decentralised economy

We obtain insight into the nature of the optımal adjustment path by considering the phase portrait of eqs (20) and (21) Stationary values of $\psi$ and $w_{x}$, respectively, require

$$
\phi \equiv \psi \lambda-f_{L}^{x}=0, \quad E \equiv-\pi_{w}^{x}-\pi_{w}^{y}-L^{0}=0
$$

The corresponding stationary loci have slopes

$$
\begin{aligned}
& \left.\frac{\mathrm{d} \psi}{\mathrm{d} w_{x}}\right|_{\phi=0}=-\frac{f_{L L}^{x} \pi_{w w}^{x}}{\lambda}>0, \\
& \left.\frac{\mathrm{d} \psi}{\mathrm{d} w_{x}}\right|_{E=0}=\frac{-\pi_{w w}^{x}}{\pi_{w p}^{y} \mathrm{~d} \tau / \mathrm{d} \psi}<0,
\end{aligned}
$$

where, from (23)

$$
\frac{\mathrm{d} \tau}{\mathrm{d} \psi}=-\frac{\lambda}{\bar{p} f_{L L}^{y} \pi_{w p}^{y}}<0
$$

In fig 2, therefore, the $\phi=0$ locus is drawn upward sloping and the $E=0$ locus downward sloping Their intersection point $\left(\hat{w}_{x}, \hat{\psi}\right)$ is the optimal end-

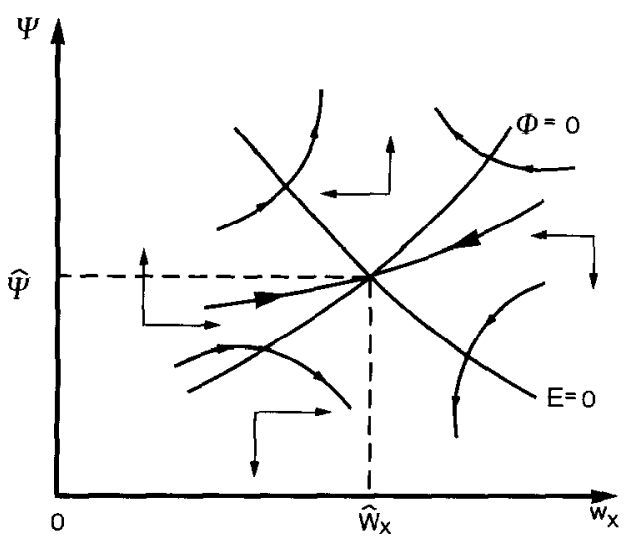

Fig 2 
point and can be reached along the stable branch indicated It is straightforward to show that $\left(\hat{w}_{x}, \hat{\psi}\right)$ is a saddle point

The phase diagram in fig 2 can be explained as follows The variable $\psi$ is the costate variable associated with the dynamic constraint in (10) It gives the marginal value of a slight acceleration in the speed of adjustment of the wage rate in $X$ The curve labelled $E=0$ shows values $\left(\psi, w_{x}\right)$ at which labour demand is equal to labour supply, $1 \mathrm{e}$ full employment It has a negative slope because the higher the wage rate in $X$, the higher must be the production subsidy $\tau$ in $Y$ required to achieve full employment [refer to fig $1(\mathrm{~b})]$, and the higher is $\tau$, the greater the employment in $Y$, the lower the marginal value product of labour there and the lower is $\psi$ [from (23)] If, for any $\psi, w_{x}$ is too high for full employment, so that we are to the right of the $E$ $=0$ locus, labour supply exceeds demand in $X$ and $w_{x}$ will be falling The converse is the case for a point to the left of the locus This explains the directions of the horizontal arrows in the figure Any point on the locus is a potential equilibrium point only as far as the labour market is concerned

The $\phi=0$ locus shows the set of $\left(\psi, w_{x}\right)$ pairs which satisfy the second equilibrium condition, namely that $\psi$ should be constant over time, which in turn [from (21)] requires that the marginal value product of labour in $X$ be equal to that in $Y$ This locus is upward sloping because the higher the marginal product of labour in $Y$, the higher is $\psi$, and the higher would have to be the marginal product of labour in $X\left(=w_{x}\right)$ to preserve the equality If, for any $w_{x}, \psi$ such as to give a point below the $\phi=0$ locus, 1 e $f_{L}^{x}>\psi \lambda$, (21) indicates that $\psi$ must be falling (recall $\pi_{w w}^{x}>0$ ), and conversely for a point above the locus This gives the direction of the vertical arrows in the figure

The only point of overall equilibrium is then the intersection of the two curves there is full employment and marginal value products of labour are equalised across sectors Moreover, if we are to the right of this point and between the two curves the $\left(\psi, w_{x}\right)$ parrs will be moving south-westward, while if we are to the left of this point and between the two curves the $\left(\psi, w_{x}\right)$ pairs will be moving north-eastward We can then find a path for these pairs, one in each segment, which terminate at the equilibrium The optimal policy is to get onto and move along one of these paths from wherever we initially happen to be

We obtain further insight into the dynamics if we note that setting $\tau(t)=0$ at any $t$ gives, from (23)

$$
\bar{p} f_{L}^{y}\left(-\pi_{w}^{y}\left(w_{y}^{0}, \bar{p}\right)\right)=\psi \lambda,
$$

and we denote by $\psi^{*}$ the unique $\psi$-value this implies In the uncontrolled model

$$
p f_{L}^{y}\left(-\pi_{w}^{y}\left(w_{y}^{0}, p\right)\right)=\bar{p} f_{L}^{y}\left(-\pi_{w}^{y}\left(w_{y}^{0}, \bar{p}\right)\right)=\psi^{*} \lambda,
$$


since employment in $Y$ is adjusted to keep $\bar{p} f_{L}^{y}$ equal to $w_{y}^{0}$ It follows that throughout the uncontrolled market adjustment $\psi$ remains constant at $\psi^{*}$ In fig 3 , therefore, the uncontrolled market economy begins at the point $\left(w_{x}^{0}, \psi^{*}\right)$ and ends up at $\left(w_{x}^{*}, \psi^{*}\right)$ The former point lies on $\phi=0$ since of course at that point

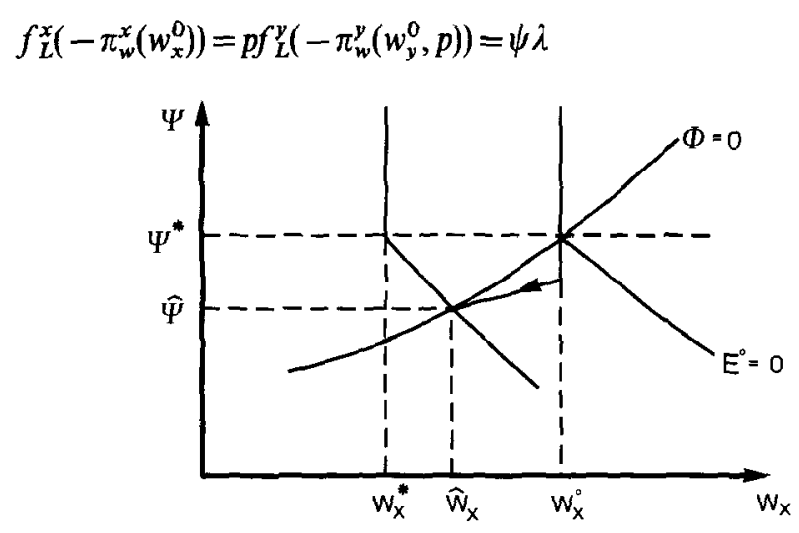

Fig 3

The $E^{0}=0$ locus is generated from

$$
E^{0} \equiv-\pi_{w}^{x}\left(w_{x}\right)-\pi_{w}^{y}\left(w_{y}^{0}, p+\tau\right)-L^{0}=0
$$

$1 \mathrm{e}$ we require labour market equilibrium at the initial price $p$ but now allow $\tau \geqq 0$ and $w_{x}$ can vary For $\psi \geqq \psi^{*}, \tau=0$, therefore $w_{x}=w_{x}^{0}$ satisfies (30) For $\psi<\psi^{*}$ we have $\tau>0$ and $w_{x}$ must increase to maintain (30) Thus, the $E^{0}$ locus is vertical for $\psi \geqq \psi^{*}$ and negatively sloped for $\psi<\psi^{*}$, as shown in fig 3

If we now reduce $p$ to $\bar{p}$, clearly the new locus

$$
\bar{E} \equiv-\pi_{w}^{x}\left(w_{x}\right)-\pi_{w}^{y}\left(w_{y}^{0}, \bar{p}+\tau\right)-L^{0}=0,
$$

must he to the left of $E^{0}$, since for every value of $\tau$ and $\psi$ a lower $w_{x}$ is required to satisfy (31) The market economy, with $\tau=0$, moves to the new corner at $\left(w_{x}^{*}, \psi^{*}\right)$, whereas the optımum is at $\left(\hat{w}_{x}, \hat{\psi}\right)$ Thus, taking $\left(w_{x}^{0}, \psi^{*}\right)$ as the starting point, the optimal policy is to pay an immediate production subsidy to put the economy on to the stable path and then continue along it - increasing $\tau$ gradually - until the optimum is reached There will of course be unemployment, both initially and along the adjustment path, since this is required to expand output of $X$, but unemployment is lower than in the uncontrolled case The dynamic shadow price of labour, $\omega_{y}$, will be JPE-E 
positive and falling [see (23)] and will be below the wage rate in $X$ at every instant until they are finally equal at the optımal end-point $F_{1} g 4$ illustrates the optımal time paths of the relevant variables

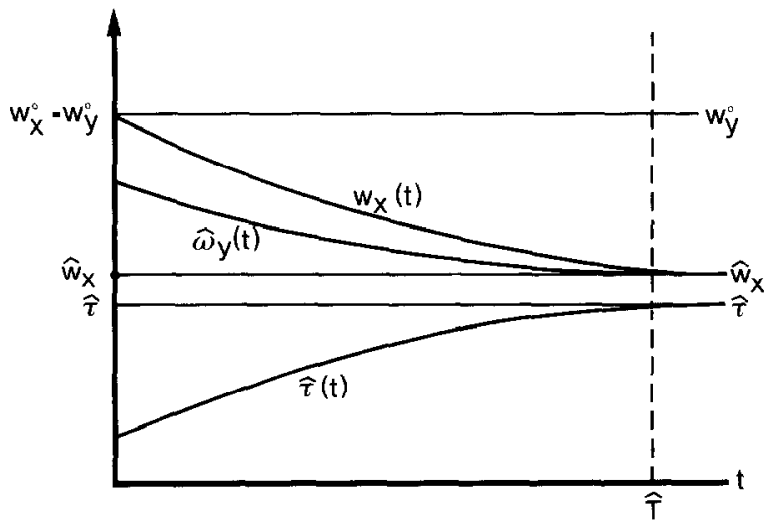

Fig 4

\section{Conclusions and generalisations}

We have shown that in an economy in which capital is sector specific, labour is imperfectly mobile and wage rates are sticky, intervention to ease the adjustment of an industry which is inefficiently large as a result of foreign competition can yield a better outcome than that resulting from market forces alone We have defined one kind of optımal policy a production subsidy which raises employment in the 'inefficient industry' above the level implied by market forces, and increases steadily to the level required to achieve the new 'neo-classical equilibrium' (which the uncontrolled economy does not itself reach) There still are, however, initial layoffs in the inefficient industry, since these are required to bring about reallocation of labour supplies to the rest of the economy. The optımal path trades off the output loss from this unemployment against the benefit of the reallocation of labour The latter, which falls steadily along the optimal path, defines the 'dynamic shadow price' of labour This is always positive, although below the wage rate in both sectors as long as there is less than full employment

There are clearly several respects in which the model could be generalised ${ }^{11}$ First, instruments other than a production subsidy could be considered As long as the subsidy is financed in a non-distortionary way it is

\footnotetext{
${ }^{11}$ Introduction of a positive discount rate makes no essential difference to the results Because the value of current output rises relative to that in the future, the optimal production subsidy increases, unemployment is lower, and convergence to the optımal end-point (unaffected by the discount rate) is slower
} 
superior to a tariff, but this need no longer be true if this assumption is relaxed The issue of the choice of instrument is then a substantive one

In addition, a wage subsidy in $X$ could be used to induce that industry to absorb any excess labour supply as soon as it presents itself, and therefore could speed up the adjustment process In other words, the stickıness of the response of $w_{x}$ to excess supply would be eliminated and the adjustment process consists only of the 'migration' of labour from $Y$ to $X^{12}$ The optimal wage subsidy in $X$ would then be whatever is required to absorb the switch of labour from $Y$, induced or controlled by the production subsidy in $Y$ Of course, in the absence of any stickiness in the migration process the dynamic optimisation problem would not exist Setting the production subsidy $\hat{\tau}$ and the wage subsidy $\left(w^{0}-w^{\prime \prime}\right)$ [see fig $1(\mathrm{~b})$ ] would immediately establish the long-run optımum ${ }^{13}$ Realistically, however, labour migration would not be instantaneous and so there is scope for a dynamic analysis

A further respect in which the model could be generalised relates to our specification of the adjustment process, which is admittedly very crude Takıng a constant speed of adjustment $\lambda$ begs a number of questions, and in particular ignores the choice-theoretic basis of the labour migration decision ${ }^{14} \mathrm{~A}$ richer specification of the adjustment process would certainly appear to be fruitful [compare the analysis of capital stock adjustment carried out by Mussa (1978)]

On the face of it the assumption that the wage rate in $Y$ is absolutely rigid while that in $X$ is flexible, though sticky, seems very restrictive The point is, however, that wage rates do not in fact adjust fast enough to ensure full employment following the 'price shock', and the burden of adjustment falls on the transfer of labour supply to and wage changes in other sectors The relative stickiness of wages is what matters, and the extreme assumption adopted here is the simplest way of representing what appears to be the case

\footnotetext{
${ }^{12}$ As in Lapan's model However, the resulting model would still be significantly different Lapan has a single wage subsidy paid uniformly across both sectors, which must do the work of two separate instruments in the present case - the production subsidy in $Y$ and wage subsidy in $X$ It is this self-imposed constraint on instruments which seems to us to create the difficulties in specifying the optimal time-path of the wage subsidy in Lapan's model

${ }^{13}$ We are grateful to one of the referees for making this point

${ }^{14}$ Again, we thank a referee for this point
}

\section{References}

Corden, Max, 1974, Trade policy and economic welfare (Clarendon Press, Oxford)

H M Treasury, 1977, Report of the working group on the economic analysis of industrial closures, mimeo

Jenkıns, Glenn $P$ and Claude Montmarquette, 1979, Estımatıng the private and social opportunity cost of displaced workers, Review of Economics and Statistics 3, 342-353

Jones, Ronald W, 1971, (A three-factor model in theory, trade and history,) in J N Bhagwatt1 et al, eds, Trade, balance of payments and growth Essays in honor of CP Kindleberger (North-Holland, Amsterdam) 
Lapan, Harvey E, 1976, International trade, factor market distortions and the optimal dynamic subsidy, American Economic Review 3, 335-346

Mussa, Michael, 1978, Dynamic adjustments in the Heckscher-Ohlın-Samuelson model, Journal of Political Economy 5, 775-791

Mussa, Michael, 1979, The two-sector model in terms of its dual, Journal of International Economics, 513-526

National Board for Prices and Incomes, 1970, Coal prices, Report no 153, Cmnd 4455 (H M S O, London)

Neary, J Peter, 1978, Short-run capital specificity and the pure theory of international trade, Economic Journal, $488-510$

Neary, J Peter, 1981, On the Harris-Todaro model with intersectoral capital mobility, Economica, 219-234 